Faculdade de Ciências Econômicas UFRGS
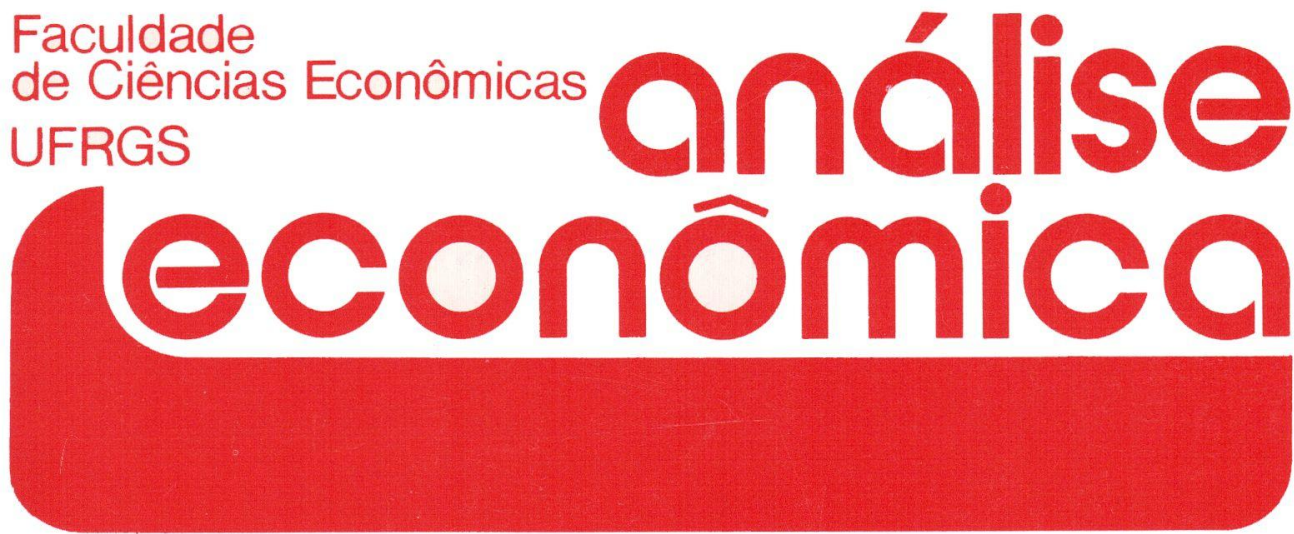

- STATE AND THE LIBERALIZATION OF THE BRAZILIAN ECONOMY

Carlos Alberto Longo

- MOEDA E CRÉDITO NA ECONOMIA BRASILEIRA: UM MODELO COM VETORES DE CORREÇÃO DE ERROS

Rolando M. Guzmán

- baSES PARA UM NOVO MOdELO DE POLítica FISCAL, PARA O BRASIL

Flávio Riani

- POR QUE OS SINOS DOBRAM? CONFLITO TRABALHISTA E SALÁRIOS DO MAGISTÉRIO PÚBLICO DO RIO GRANDE DO SUL, 1974-1991

Carlos Henrique Horn

Roberto Balau Calazans

- A POLÍtica MONETÁRIa E AS TAXAS de JUROS NO PLANO COLLOR

Lauro Lobo Burle

- DIFUSÃo E TRANSFERÊNCIA DA TECNOLOGIA DE PRODUÇÃO DE CIMENTO NO BRASIL

Maria Cristina Pereira de Melo

- SISTEMA FINANCEIRO BRASILEIRO: UMA PROPOSTA dE disCuSSÃo

Luiz Felipe Serpa

- TEORIA ECONÓMICA DO CASAMENTO E DO Divórcio

Giácomo Balbinotto Neto

- RESENHA

VARGAS: O CAPITALISMO EM CONSTRUÇÃO, DE PEDRO C. D. FONSECA

João Rogério Sanson

- LIVROS RECEBIDOS

Claudine Saldanha César
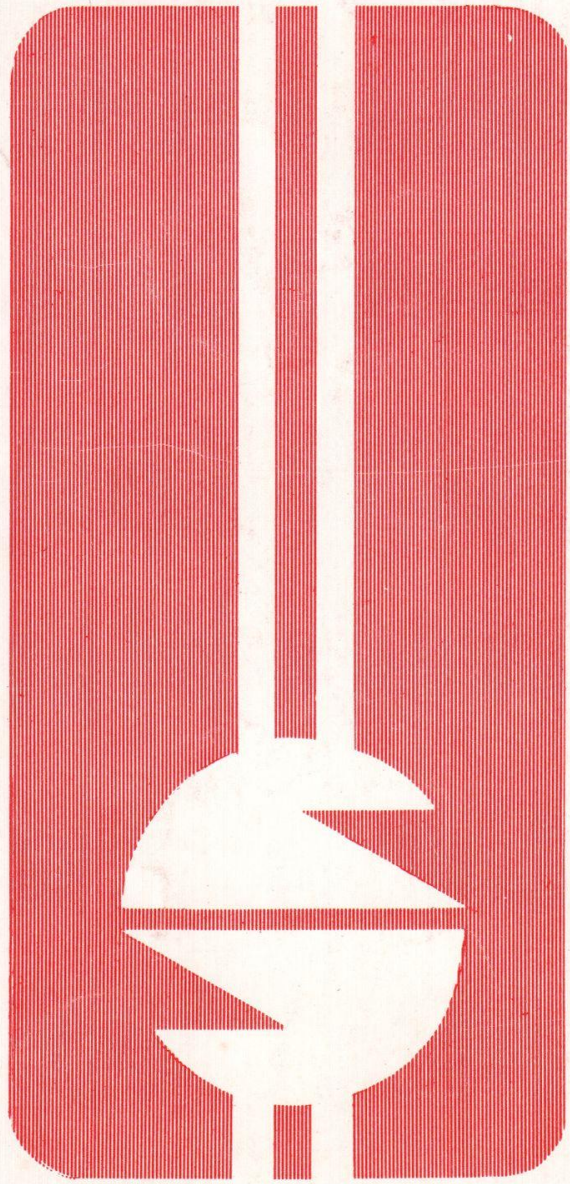
UNIVERSIDADE FEDERAL DO RIO GRANDE DO SUL

Reitor: Prof. Hélgio Henrique Casses Trindade

FACULDADE DE CIÉNCIAS ECONÔMICAS

Diretora: Prof ${ }^{a}$ Yeda Rorato Crusius

CENTRO DE ESTUDOS E PESQUISAS ECONÔMICAS

Diretor: Reinaldo Ignacio Adams

DEPARTAMENTO DE CIENNCIAS ECONÔMICAS

Chefe: Prof. Fernando Ferrari Filho

CURSO DE PÓS-GRADUAÇÃO EM ECONOMIA

Coordenador: Prof. João Rogério Sanson

CURSO DE PÓS-GRADUAÇÃO EM ECONOMIA RURAL

Coordenador: Prof. Juvir Luiz Mattuella

CONSELHO EDITORIAL: Achyles Barcelos da Costa, Aray Miguel Feldens, Atos Freitas Grawunder, Carlos Augusto Crusius, ErnaniHickmann, Fernando Ferrari Filho, João Rogério Sanson, Juvir Luiz Mattuella, Maria Imilda da Costa e Silva, Nali de Jesus de Souza, Nuno Renan Lopes de Figueiredo Pinto, Otília Beatriz Kroeĩ Carrion, Otto Guilherme Konzen, Paulo Alexaridre Spohr, Pedro Cezar Dutra Fonseca, Reinaldo Ignacio Adams, RobertsCamps Moraes, Valter José Stülp, Yeda Rorato Crusius, David Garlow (Wharton Econometrics Forecasts Association, E.U.A.), Edgar Augusto Lanzer (UFSC), Eleutério F. S. Prado (USP), Fernando Holanda Barbosa (FGV/RJ), Gustavo Franco (PUC/RJ), Joaquim Pinto de Andrade (UiNB), Juan H. Moldau (USP), Werner Baer (Univ. de Illinois, E.U.A.)

COMISSÃO EDITORIAL: Atos Freitas Grawunder, Reinaldo Ignacio Adams, Pedro Cezar Dutra Fonseca, Roberto Camps Moraes.

EDITOR: Nali Jesus de Souza

SECRETARIA: Maria Ivone de Mello (normalização), Vanete Ricacheski (revisão de textos)

FUNDADOR: Prof. Antônio Carlos Santos Rosa

Os materiais publicados na Revista Análise Econômica são de exclusiva responsabilidade dos autores. É permitida a reprodução total ou parcial dos trabalhos, desde que seja citada a fonte.

Aceita-se permuta com revistas congêneres. Aceitam-se, também, livros para divulgação, elaboração de resenhas ou recensões.

Toda correspondência, material para publicação (vide normas na $3^{a}$ capa), assinaturas e permutas devem ser dirigidos ao seguinte destinatário:

PROF. NALI DE JESUS DE SOUZA

Revista Análise Econômica

Av. João Pessoa, 52

90040-000 - PORTO ALEGRE (RS), BRASIL

Telefones: (051) 228.1633 - 224.6022 - Ramais 3348 ou 3440

FAX: (051) 225.1067 


\section{A TEORIA ECONÔMICA DO CASAMENTO E DO DIVÓRCIO}

\section{Giácomo Balbinotto Neto*}

\section{SINOPSE}

O objetivo deste artigo é fazer uma breve resenha sobre a teoria econômica do casamento c do divórcio, apresentando seus principais pressupostos e conclusōes, bem como as críticas a ela dirigida.

\section{INTRODUÇÃO}

O objetivo deste artigo é o de fazer uma breve resenha sobre à teoria econômica do casamento e do divórcio.

A análise econômica do casamento e do divórcio surge e se desenvolve principalmente a partir da primeira metade dos anos 70 , em torno dos trabalhos pioneiros de Becker $(1973,1974)$, quando os economistas passam a utilizar a análise econômica para explicar a família, ${ }^{1}$ procurando analisar, a partir de um enfoque essencialmente econômico, por que as pessoas se casam, com quem se casam, quando se casam, se vale a pena casar-se, quando e por que se separam, os aspectos econômicos do namoro, do noivado e do amor, as formas de casamento, bem como ar implicações de tais fatos sobre o crescimento populacional, as taxas de cruscimento econômico, a demanda por bebês, por exemplo.

* Mestre em Economia (IEPE/UFRGS) Professor do Departamento de Ciências Econômicas da UFRGS e Assessor Econômico da FIERGS.

O autor agradece aos professores João Rogério Sanson (IEPE/UFRGS) e Eduardo Zimmermann (ESEADE e Universidade de Santo Andrés - Buenos Aires), bem como aos participantes dos seminários realizados na ESEADE e no IEPE/UFRGS pelas críticas e sugestōes a versōes preliminares deste artigo. Contudo, como de praxe, os erros, deficiências e possiveis omissōes, bem como as idéias aqui exp̧ustas são de minha exclusiva responsabilidade. $O$ trabaltho contou com o apoio financeiro do Instituto Liberal do Rio Grande do Sul.

1 Segundo Blaug (1980,p 267-268), nesta abordagem - “ a família é vista como uma unidade de produção multipessoal que maximiza uma função de produção cujos fatores de produçāo são mercadorias que o mercado oferece, o tempo, as habilidades e os conhecimentos dos diferentes membros da familia."

\begin{tabular}{|l|l|ll|l|}
\hline ANÁLISE ECONÔMICA & ANO 10 & N:18 & SETEMBRO/92 & P. 125-141 \\
\hline
\end{tabular}


Segundo Becker(1973,p.814; 1988,p.1), a abordagem econômica da família contribui para explicar uma série de fatos que se observaram recentemente, como o declínio das taxas de nascimento, a rápida expansão da participação da força de trabalho feminina no mercado de trabalho, o explosivo avanço nas taxas de divórcio e as implicações sobre o crescimento econômico. Além disso, este novo enfoque, também chamado a nova economia da família (cf. Blaug, 1980,p.297 e Ekelund e Hebert,1990,p.612), não seria apenas uma aplicação da teoria microeconômica tradicional a questões antes vistas principalmente pela sociologia, antropologia e psicologia social, mas também um novo enfoque sobre o comportamento do consumidor. Segundo Becker (1986,p.169):

\begin{abstract}
A teoria tradicional do consumidor é essencialmente uma teoria do consumidor individual, e é quase estéril, ainda que não seja totalmente (o importante teorema das curvas de demanda negativamente inclinadas a salva da esterilidade total). Em contraste, a nova teoria do consumidor é uma teoria referente a uma família de vários membros com uma função de utilidade independente, e que se centra sobre a coordenação e interação entre os membros a respeito das decisões referentes aos filhos, ao casamento, a divisão do trabalho relativa ac horas traballhadas e as inversões em capacitação para atividades extramercado, a prevenção dos seus membros contra o azar, as transferências intergeraçôes de seus membros etc... Os economistas se encontram, portanto, no ínicio de sua tarefa de atribuir à família esse papel dominante na sociedade que tradicionalmente foi atribuído aos sociologos, antropólogos e psicólogos.
\end{abstract}

Segundo McKenzie e Tullock (1980,p.139), o enfoque econômico do casamento e do divórcio encara a família como uma unidade de produção, como uma empresa que utiliza deterninados insumos - que são comprados tanto dentro como fora dos mercados para satisfazer as necessidades dos seus membros. Ainda segundo eles - "o objetivo explícito desta abordagem é o de destacar a importância do contrato matrimonial, dos problemas dodivórcioe das implicações econômicas do amor, bem como dos princípios organizativos da família."

Ainda segundo eles, o enfoque econômico não tem a pretensão de fornecer um conhecimento completo daqueles problemas, mas sim de ser um entre os possíveis pontos de vista que podem ser complementados por outras disciplinas.

Á mesma opinião é expressa por Becker (1986,p.110) quando nos diz que - embora a abordagem econômica possa prover uma estrutura de análise bastante útil para entender todo o comportamento humanc, outras variáveis não econômicas poderiam afetar tal comportamento. Entretanto, segundo ele, a abordagem econômica provê uma estrutura unificada para a compreensão do comportamento humano em sua totalidade.

O artigo está dividido em mais três seções além desta introdução. Na seção dois apresentamos um resumo da abordagem econômica do comportamento humano baseado principalmente nos trabalhos de Becker (1986) e McKenzie e Tullock (1980). Na seção três, apresentamos a teoria econômica do casamento e do divórcio, destacando os pontos principais e algumas de suas implicações. Por fim na seção quatro, apresentamos as conclusões do artigo tecendo breves considerações com base no que foi visto nas seções precedentes. 


\section{A ABORDAGEM ECONÔMICA DO COMPORTAMENTO HUMANO}

Nesta seção apresentamos um resumo da abordagem econômica do comportamento humano, baseando-nos principalmente em Becker (1986) e McKenzie e Tullock (1980).

Segundo Becker (1986,p.108), geralmente tem-se argumentado que o objeto de estudo da economia seria o estudo da alocação dos bens materiais para satisfazer as necessidades materiais do setor mercado e da alocação dos recursos escassos entre fins alternativos. Contudo elas nada nos dizem sobre o que vem a ser a abordagem econômica em si mesma. Para ele, este seria o principal fator que diferenciaria a Economia das outras disciplinas nas ciências sociais, além de ser a única poderosa, no sentido de que pode integrar sobre uma mesma abordagem e com um mesmo instrumental uma séries de comportamentos, desde a demanda por bebês (cf. McKenzie e Tullock, 1980) até o suicídio (cf. Hamermesch e Soss, 1974). Além disso, ainda segundo ele:

... a abordagem econômica é uma abordagem compreensiva que ś aplicável a todo o comportamento humano, seja este comportamento envolvendo preços monetários ou preçossombra imputados, decisões repetidas ou infrequentes, decisões fundamentais ou de menor importância, com fins emocionais ou mecânicos, à pessoas ricas ou pobres, homens ou mulheres, adultos. ou crianças, pessoas brithantes ou estúpidas, pacientes ou terapeutas, homens de negócio ou políticos, professores ou estudantes (cf.Becker,1986,p.112).

No que diz respeito aos pressupostos fundamentais da abordagem econômica ao comportamento humano, é assumicio que:

(i) os indivíduos maximizam sua utilidade;

(ii) existem mercados que coordenam as ações dos diferentes participantes, de modo que seus comportamentos sejam consistentes;

(iii) as preferencias dos indivíduos são estáveis, isto é, elas não mudam de maneira significativa em curtos períodos de tempo.

Segundo Becker (1986,p.110), a combinação destes três pressupostos configurariam os aspectos fundamentais da abordagem econômica. Resumindo sua posição a respeito, ele nos diz que:

Oponto central do meu argumento é que o comportamento humano nãoé compartimentalizado, algumas veres baseado sobre a maximização, algumas vezes não, algumas vezes motivado por preferências estáveis, algumas vezes motivado por preferências voláteis, algumas vezes resultando numa acumulação ótima de informação, algumas vezes não. Em vez, todo o comportamento humano pode ser visto como envolvendo participantes que maximizam sua utilidade de um conjunto de preferências e que acumulam uma quantidade ótima de informação e de outros insumos numa variedade de mercados. 
Outro pressuposto que está implícito é que os indivíduos que agem e que tomam decisões são racionais. A este respeito McKenzie e Tullock $(1980, p .18)$ nos dizem:

\begin{abstract}
Do ponto de vista da análise econômica é irrelevante que os sujeitos tomem decisões livres ou que estejam "programados" para tomá-las. Somente necessitamos dar-nos conta de que, efetivamente, tomam decisões. Tal postura têm algumas implicações. Primeiro, em economia se supõe que as pessoas são "racionais" no sentido de que são capazes de determinar aquilo que querem, dentro de seus limites, e que lutarão por conseguir tanto daqueles desejos quanto seja possível. As pessoas são capazes de compensar as forças biológicas e ambientais que, do contrário, determinariam suas ações. Na medida em que são capazes de fazê-lo depende dos recursos a sua disposição e de seu desejo de vencer aquelas forças.
\end{abstract}

Quanto à questão da incerteza, resultante principalmente da informação imperfeita, é suposto que quando o indivíduo tiver que optar entre um conjunto de alternativas, escolherá aquela que resultar num maior valor esperado.

Por fim, é suposto que toda ação humana envolve custos e benefícios, podendo estes ser monetários ou não. Os custos referem-se ao valor da melhor alternativa quèse abriu mão quando se efetuou determinada escolha, ou seja, ao custo de oportunidade.

$\mathrm{Na}$ análise do comportamento humano, o enfoque econômico utiliza principalmente modelos que procuram representar os aspectos essenciais da conduta humana. Neste sentido McKenzie e Tullock (1980,p.12) argumentam que, para compreender alguns fenômenos sociais, primeiro é preciso entender por que as pessoas se comportam de determinada maneira e não de outra qualquer. Para tal énecessário que se tenha um modelo que dê conta das motivações e da organização da conduta humana, a partir da qual seja possível interpretar os fatos observados. Assim, a teoria econômica utiliza o método hipotético dedutivo para interpretar os fenômenos relacionados ao comportamento humano.

Outro aspecto metodológico referente à teoria econômica do comprortamento humano é seu individualismo metodológico, isto é, todas as implicações e hipóteses têm por base as ações e interações dos indivíduos. A este respeito McKenzie e Tullock (1980) são enfáticos:

O ponto principal do estudo da teoria econômica é o indivíduo. É o indivíduo que tem valores, quem elege, se as liberdades se tomam como dadas, que rege suas açôes. Todas as decisōes e atuações de grupo são consideradas em termos de decisões coletivas e de açōes dos indivíduos. Os objetivos sociais são tomados em conta somente na medida em que refletem os valores coletivos ou as ações dos indivíduos.

Por fim, é dito que a abordagem econômica do comportamento humano é amoral, no sentido de que ela não se ocupa do que deveria ser, ou de como os 
indivíduos deveriam se comportar, ela procura de explicar por que se comportam e agem de determinada maneira e como e quando o fazem.

As principais críticas dirigidas à teoria econômica do comportamento humano são as seguintes:

(i) a teoria econômica do comportamento humano teria a pretensão de fornecer um conhecimento completo do comportamento humano. Tal crítica não tem razão de ser, visto que os economistas reconhecem as limitações do seu enfoque e não desprezam as contribuições de outros campos do conhecimento científico. Segundo McKenzie e Tullock (1980,p.12), a teoria econômica do comportamento humano não tem a pretensão de fornecer um conhecimento completo de todo o comportamento humano, mas sim de ser um entre os possíveis pontos de vista que podem ser complementados por outros campos. Além disso, segundo Becker (1986,p.1 10), a abordagem econômica, mesmo para aqueles que acham que ela seja aplicável a todo o comportamento humano, reconhecem que muitas variáveis não econômicas também afetam ocomportamento humano, eque tais variáveis, bem como as técnicas e descobertas de outros campos científicos, como a Antropologia, Psicologia e Sociologia, podem contribuir para o seu entendimento. Contudo a abordagem econômica seria a única que poderia integrar todos os comportamentos;

(ii) a abordagem econômica do comportamento humano traz implícita uma visão extremamente materialista do ser humano. Segundo McKenzie e Tullock (1980,p.19), tal crítica seria completamente injustificada, visto que, o que se postulou foi que, simplesmente, os indivíduos têm desejos, e que estes podem ser incorporados tanto a coisas materiais, como alimentos, eletrodomésticos, carros etc, como a objetos de natureza estética, intelectual e espiritual;

(iii) os modelos utilizados pelos economistas seriam "irrealistas" no sentido de que não espelham oque realmente ocorre no mundo real. Embora reconhecendo que, idealmente, numa análise do comportamento humano mais "completa" se levasse em conta "todos" os aspectos que influenciassem tal comportamento, isto seria impossível do ponto de vista prático, visto que, o ser humano tem uma capacidade limitada para armazenar e relacionar os milhões, quando não bilhões de dados e interrelações que estão envolvidos em seu comportamento. Assim, para chegar a deduções e predições que sejam significativas, eles restringem deliberadamente suas informações, abstraindo da realidade os aspectos considerados relevantes, de modo que possam tornar seus trabalhos manejáveis e obterem resultados satisfatórios. Isto também tem importantes implicações para as predições derivadas dos modelos, já que, por sua própria natureza, eles não "reproduzem" a realidade tal como ela é, a sua utilidade e aceitabilidade derivam da sua utilidade na explicação dos fenômenos que ocorrem e na elaboração de predições corretas (cf. Friedman, 1953). Além disso, como destacam McKenzie e Tullock 
(1980,p.12), para compreender determinados fenômenos sociais, o passo prévio é entender por que as pessoas se comportam de determinada maneira e, para tal, é necessário que se tenha um modelo sobre as motivações e a organização de sua conduta, a partir da qual seja possível interpretar os fatos observados;

(iv) a teoria econômica do comportamento humano seria amoral e isenta de qualquer juízo de valor. A este respeito a resposta de McKenzie e Tullock (1980,p.16) nos parece exemplar:

O enfoque do economista $€$ amoral. A análise econômica não se ocupa do que deveria ser, ou de como deveriam se comportar os individuos, mas do conhecimento sobre o porquê as pessoas se comportam e como o fazem. De acordo com isto, nossa análise está vacinada (na medida em que isto for possível) dos nossos proprios valores pessoais. Tratamos cada tema como algo que deve ser analisado e entendido e para fazê-lo devemos evitar a tentação de julgar uma forma determinada de comportamento como menosprezível, imoral, boa ou má

(v) por fim, o ponto que tem levado às maiores controvérsias é o suposto da racionalidade e sua maximização. Por exemplo, Hunt (1982,p.494-495) critica Mckenzie e Tullock (1980) pela adoção de tal pressuposto, questionando se eles realmente acreditam que os seres humanos sejam máquinas racionais e calculadoras de prazer, considerando o seu trabalho como uma simples banalidade do triunfo do utilitarismo individualista. Contudo os economistas que advogam a validade de tais pressupostos nos dizem que o requisito da racionalidade é muito suave e não é fundamental na análise econômica, pois como argumentou Becker (1962), não é essencial que as pessoas sejam "racionais" para que se cumpram os postulados básicos da análise econômica. Já McKenzie e Tullock (1980,p.66-78) vão mais além, salientando que a racionalidade, no sentido em que é utilizada na análise econômica, não caracterizaria somente o ser humano considerado "normal", mas também os "loucus", aves, ratos e outros animais. Suas evidências indicam que tanto os indivíduos como os animais se comportam de modo consistente com os pressupostos do comportamento racional, quais sejam apresentam curvas de demanda negativamente inclinadas, procuram comprar no mercado mais barato e ajustam o seu consume $\mathrm{sm}$ termos de preço. O que eles procuraram demonstrar, através daqueles exemplos, é que a exigência da racionalidadé utilizada na análise econômica é muito modesta, e que não se está dizendo nada de especial ou lisonjeiro, quando se diz que os seres humanos são racionais. Contudo, quando se afirma que os seres humanos não são racionais, esiáse dizendo algo ofensivo, está-se dizendo que até os animais uniceluiares são mais brilhantes e mais capazes de formular decisões de consumo inteligentes que a média dos seres humanos.

$\mathrm{Na}$ seção seguinte, veremos uma aplicação da abordagem econômica do comportamento humano, qual seja, a teoria econốmica da formação e da dissolução da família, procurando ver como a teoria econômica pode oferecer interessantes "insights" para seu entendimento. 


\section{A TEORIA ECONÔMICA DO CASAMENTO E DO DIVÓRCIO}

O objetivo desta seção é o de fazer uma breve apresentação dos principais resultados obtidos pela teoria econômica do casamento e do divórcio, tomando por base principalmente os trabalhos de Becker $(1973,1974,1981)$ e McKenzie e Tullock (1980).

Segundo Becker (1981,p.10-11), a abordagem econômica não se limita apenas à análise dos bens e os desejos materiais ou do mercado, em que se efetuam transações monetárias e que, conceptualmente, não se pode distinguir entre transações de máximo interesse e decisões emocionais. Parã ele, a abordagem econômica proporciona um marco teórico que pode ser aplicado a todo o comportamento humano. Assim, visto que a análise foi aplicada com relativo sucesso para explicar o comportamento humano fora do setor mercado na análise da demanda por filhos (cf. Becker, 1981 e Mckenzie e Tullock, 1980), crime (cf. Ehrlich 1975) e suicídio (cf. Hammermesh e Soss, 1974), ele procurou aplicar a análise econômica ao comportamento dos indivíduos na formação e dissolução da família e, mais especificamente, ao casamento, divórcio, procura do cônjuge e formas de casamento.

A teoria econômica do casamento e do divórcio surge e se desenvolve na primeira metade dos anos 70, a partir dos trabalhos pioneiros de Becker $(1973,1974)$, bem como de outros que se produzem principalmente no Departamento de Economia da Universidade de Chicago. Becker $(1973,1974)$ procura mostrar como a moderna análise econômica pode ser utilizada para analisar as decisões dos indivíduọs na formação e dissolução da família. Além disso, a análise econômica do casamento pode proporcionar importantes implicações no que se refere ao número de nascimentos, crescimento populacional, da participação da mulher no mercado de trabalho. Já para McKenzie e Tullock (1980), o objetivo da abordagem econômica seria o de destacar a importância do casamento, dos problemas suscitados pelo divórcio e das implicações econômicas do amor, bem como dos princípios organizativos da família.

A seguir procuramos expor os principais pontos e implicações derivadas da análise sconômica do casamento e do divórcio.

\subsection{A Definição de Casamento}

Do ponto de vista econômico, o casamento é visto como uma relação contratual estabelecida entre um homem e uma mulher (casamento monogâmico), entre um homem e duas ou mais mulheres (casamento poligênico), entre uma mulher e dois ou mais homens (casamento poliândrico) ou mesmoentre indivíduos do mesmo sexo (casamento homossexual). Mesmo que tais contratos não estejam "escritos", eles são fundamentais em toda e qualquer sociedade, pois como salientou Stigler (1991,p.197), eles forneceriam a base institucional para a perpetuação da raça humana. Para Becker $(1973,1981)$, o casamento pode ser 
definido como um contrato de longo prazo entre um homem e uma mulher (nocaso da monogamia), o qual implica que eles irão viver juntos e dividirão a mesma casa. Além disso, ele assume que o casamento irá ocorrer se, e somente se, ambos estiverem numa situação melhor, istoé, se aumentarem sua renda total (cf. Becker, 1981,p.62-66 e Freiden, 1974). Entretanto, como ele ressalta, tal decisão baseiase na renda ou utilidade total esperada, já que o futuro não é conhecido com certeza.

McKenzie e Tullock (1980) também definem o casamento em termos contratuais entre os membros do mesmo sexo ou de sexos diferentes, onde é assumido, implícita ou explicitamente, que ambas as partes aceitem as cláusulas do contrato e que o respeitem, bem como se estabeleçam regras que regerão as decisões familiares e as possíveis modificações no contrato, visto que não é possível prever todas as questões referentes à vida familiar que irão ocorrer durante o casamento.

\subsection{Os Aspectos Econômicos da Busca do Cônjuge e do Namoro}

A teoria econômica da busca do cônjuge e do namoro está baseada fundamentalmente na teoria econômica da informação, como desenvolvida por Stigler (1961). Vejamos primeiro a questão da busca do cônjuge.

Para Becker (1974,p.21) - " a decisão de casar pode ser vista inicialmente como uma atitude de uma pessoa de quando entrar no mercado de casamcnto e procurar o cônjuge apropriado". ${ }^{2}$

Dada a decisão de entrar no mercado de casamento, ela passará a procurar o cônjuge que considere ideal, dadas as suas limitações de recursos. Como é assumido que os indivíduos são racionais, a procura irá continuar até que o valor esperado de qualquer melhora no par que possa encontrar não seja maior que os custos do seu tempo e de outros insumos gastos nesta procura adicional. Desta teoria econômica da busca do cônjuge deviram interessantes "insights", entre os quais pode-se destacar os seguintes:

(i) a procura será mais longa quanto maiores forem os benefícios da procura audicional (cf. Becker, 1974,p.522);

(ii) a procura será mais longa quanto mais variáveis forem os pretendentes potenciais devido aos ganhos esperados de uma experimentação adicional. Isto implica que, ceteris paribus, o casamento tenderá a ser mais tarde em sociedades dinâmicas, móveis ediversificadas, do que em sociedades estáticas e homogêneas (cf. Becker, 1974, p.522);

2 Segundo Becker (1981,p.61), a expressão mercado matrimonial ê empregada num sentido metafórico, implicando que o mesmo está, em grande parte, sistematizado e estruturado. 
(iii) quanto mais raras forem as características desejadas, mais altos tendem ser os custos da procura, para um dado benefícioe, portanto, mais tempo demorara a se encontrar o cônjuge considerado adequado (cf. Becker et alli, 1977,p.522);

(iv) quanto maiores forem os benefícios do casamento, maiores serão os custos que os cônjuges estarão dispostos a incorrer na seleção, o que implica que, quanto maiores forem os benefícios em termos de eficiência obtida na produção familiar e quanto maior seja o "amor" que se sente pela pessoa com quem se casa, maiores serão os custos, em termos de tempo e esforço que um indivíduo dedicará à busca. Isto não implica que não se cometam erros, mas somente que se incorrerá em maiores custos para evitá-los (cf. McKenzie e Tullock, 1980,p.151);

(v) quanto maiores forem os custos e dificuldades para a obtenção do divórcio, maiores serão os custos incorridos na busca do cônjuge, pois a impossibilidade do mesmo implica que a escolha equivocada lhe acarretará um custo muito maior do que no caso em que fosse possível a dissolução (cf. Becker, 1974,p.22).

- Tal análise pode ser vista na Figura 1 abaixo. No eixo das abcissas temos a quantidade de informação e no eixo das ordenadas os custos e o benefícios derivados da obtenção de uma informação adicional. A curva BB1 representa os benefícios da obtenção de uma informação adicional. A inclinação da curva é negativa, indicando que, quanto maior o nível de informação demandada, menores

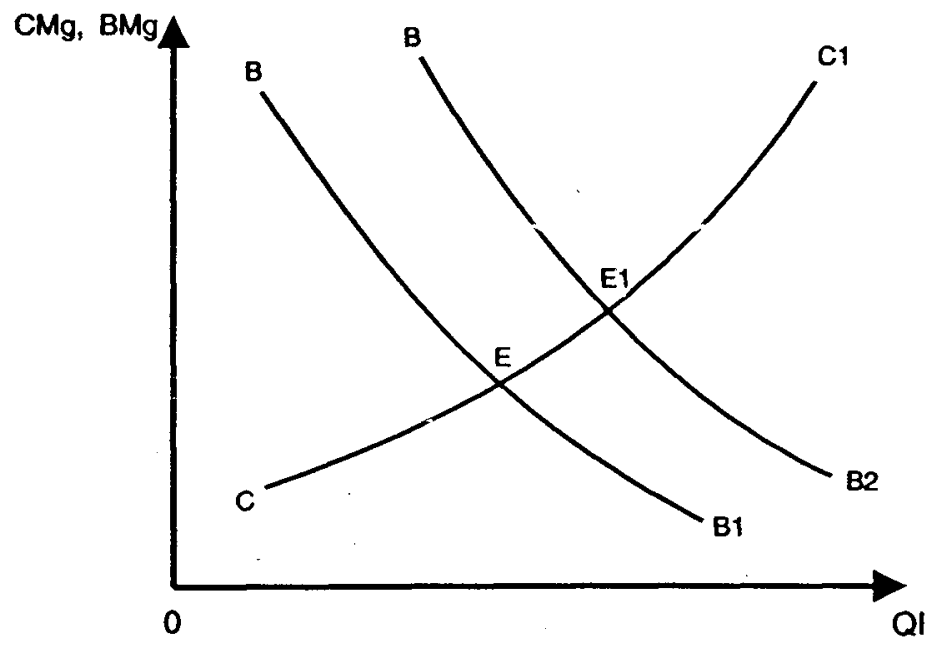

Figura 1 
serão os benefícios marginais desta informação e dos recursos invertidos na sua obtenção. A curva CC1 representa os custos marginais da obtenção de informação. Quanto maior for a quantidade de informação desejada, maiores serão os custos de sua obtenção. A quantidade ótima de informação é dada pelo ponto $\mathrm{E}$, onde os custos e benefícios marginais são iguais.

No caso em que ocorra um aumento dos benefícios do casamento, maior será o valor atribuído a uma informação adicional, a fim de se evitar um possível engano. Assim, teremos um deslocamento da curva BB 1 para BB2. O novo ótimo é dado pelo ponto E1. Isto implica que os indivíduos estarão dispostos a incorrer em maiores custos a fim de obter uma maiore melhor informação sobre o seu futuro cônjuge.

Agora supondo que o indivíduo tenha encontrado o cônjuge adequado segundo suas preferências, ele deve decidir se aceita aquele cônjuge ou continua a procurar outro melhor. Para tomar tal decisão ele pondera os custos e benefícios de tal atitude. Segundo Becker et alli (1977,p.1147), o custo de continuar a procura é dado pela soma dos custos da procura e qualquer renda perdida ou informação desperdiçada por permanecer solteiro, em vez da renda ganha e da informação obtida durante o namoro ou noivado. Já o benefício esperado de continuar a procura é igual ao produto da probabilidade de encontrar um cônjuge preferível vezes o aumento esperado na riqueza de t $\hat{c}$-lo encontrado.

No que diz respeito aos aspectos econômicos do namoro e do noivado, ele é visto como um período no qual os cônjuges procuram obter informações adicionais e formular as cláusulas do contrato de casamento. Tal aspecto é destacado principalmente por McKenzie e Tullock (1980,p.141), que nos dizem o seguinte:

\footnotetext{
O objetive fundamental do noi vado e do namoro pode consistir em proporcionar an casal uma oportunidade para elaborar aquelas cláusulas e para dar corpo ao contrato conforme o qual irão viver. $O$ contrato pode incluir, por exemplo, uma cláusula em relação ao número de filhos, quem irá fazer os trabalhos domésticos, quem irá cortar a grama, quais as decisões que irão ser tomadas democraticamente numa assembléia familiar e quais as que serão tomadas institucionalmente.
}

Assim, o namo:o e o noivado têm um papel econômico fundamental na constituição do casamento, pois ele implica tanto a utilizaçãn de determinados recursos na obtenção de informação adicioial sobre o cônjuge, bem como no estabelecimento de normas que regerão o casamento. Os benefícios do namoro e do noivado refletem-se num casamento mais estável e duradouro, supondo que durante aquele período se tenha obtido todas as informações relevantes sobre o cônjuge e se firmado, implícita ou explicitamente, o maior número de cláusulas que regularão a vida conjugal. 


\subsection{A Teoria Econômica do Casamento}

Vejamos agora a análise econômica do casamento, baseando-nos principalmente nos trabalhos de Becker (1973,1974,1981), McKenzie e Tullock (1980). O casamento é visto como uma atitude racional que tomam os indivíduos no sentido de maximizarem sua renda e utilidade. Segundo Becker (1973,p.816), o casamento ocorre se, e somente se, ambos os cônjuges estiverem numa situação melhor do que permanecerem solteiros, istoé, se ambos aumentarem sua renda como mesmo.

O conceito de renda adotado por Becker é bastante amplo, não se limitando apenas a renda monetária obtida no setor mercado, ela abrange todo um estilo de vida, incluindo os filhos, a produção de bens e serviços domésticos e uma vida social agradável; neste sentido, como observou Stigler (1991,p.197), - “a renda é muito mais que dólares". Contudo deve-se ressaltar, que tal decisão deve-se basear na utilidade esperada, visto que o futuro não é conhecido com certeza.

O que se está na realidade procurando fazer na análise econômica do casamento é ir além das explicações óbvias para o casamento, tais como a atração física e sexual e o desejo de ter filhos. Para isto, deve-se comparar os custos e os benefícios do casamento. Entre os custos podemos destacar os seguintes:

(i) a perda de independência. Segundo McKenzie e Tullock (1980,p. 143), este seria um dos mais importantes custos do casamento, visto que, depois dele, não se está mais completamente livre para fazer o que se deseja, pois deve-se considerar os efeitos que as ações de um dos cônjuges acarretaria sobre os demais membros da família;

(ii) os custos da tomada de decisão. Visto que uma família é composta por mais de um membro, há o custo das tomadas de decisão referentes ao tempo e ao desgaste requerido para chegar a elas. Some-se a isto, o fato de que tais custos aumentam significativamente quando o número de pessoas na família aumenta. Contudo, embora possam ser estabelecidos alguns ciispositivos que visem reduzir tais custos, os mesmos não deixam de existir;

(iii) ao custo de oportunidade referente as oportunidades perdidas de casarse com outra pessoa que não se conhece até o momento, mas que teria proporcionado um nível de satisfação mais elevado da satisfação;

(iv) os custos de não conseguir os bens e serviços que melhor satisfaçam suas preferências em quantidade e qualidade.

No que diz respeito aos benefícios do casamento, eles referem-se principalmente a capacidade que tem a família de produzir os bens e serviços desejados 
pelos cônjuges e pela redução dos custos proporcionados pelo casamento e pela convivência. Entre estes podemos destacar os seguintes:

(i) a produção de bens e serviços que, em situações diferentes do casamento, não têm um substituto perfeito, tais como bebês, o prestígio e o "status" proporcionado por ele, a vida sexual no "plano familiar", etc. Entretanto, como salientaram McKenzie e Tullock (1980,p.146), estes bens, embora possam ser produzidos fora do casamento, sugere-se que, no ambiente familiar, eles adquirem características especiais que passam a ser valorizados por isto;

(ii) as economias de escala que são obtidas na produção familiar, isto é, é possível produzir uma maior quantidade de bens e serviços ao nível familiar doque várias unidades familiares compostas de uma só pessoa;

(iii) ao intercâmbio e especialização obtido na produção na unidade familiar, de modo que cada membro possa maximizar o uso de seus recursos e aptidões.

Além destes, há ainda outros fatores não econômicos que afetam os ganhos do casamento. Segundo Becker (1980,p.822), a beleza, inteligência e educação afetariam a produtividade e as oportunidades de mercado. Isto explicaria, segundo ele, por que as pessoas menos atraentes, inteligentes e educadas têm menos probabilidade de se casar. Assim, quanto maiores forem os ganhos do casamento, em relação aos custos, maior tenderá a ser a fração das pessoas que estarão dispostas a casar.

No que se refere especificamente as taxas salariais e a renda não mercado, segundo Freiden (1974,p.s38), se tanto o tempo dos homens como das mulheres são substitutos perfeitos, tanto na produção familiar como no mercado, não haveria ganhos relativos no casainento e ambos tenderiam a permanecer solteiros. Contudo, no caso em que aqueles fatores forem diferentes, como por exemplo, quando o salário do homem for superior ao da mulher, o homem irá se especializar na produção para o mercado e a mulher na produção doméstica. Ainda segundo ele, os ganhos do casamento e a proporção de mulheres casadas devem estar positivamente relacionados com a taxa salarial relativa entre homens e mulheres, de modo que, quanto maior for a diferença naquela taxa, maiores serão os incentivos para se casar e maior tenderá a ser a taxa de casamento.

\subsection{Os Aspectos Econômicos do Amor}

Segundo Becker (1974,p.12), os economistas nada teriam a dizer ou explicar por que uma pessoa ama outra. Contudo, desde que amar implica preocupar-se sobre o que acontece com o outro, a análise econômica tem algo a dizer sobre os seus efeitos no casamento. 
O modo pelo qual o amor ou a preocupação com o que acontece com o cônjuge é visto é através do nível de satisfação ou de utilidade de outra pessoa, sendo medida através de sua função utilidade. Assim, se $\mathrm{M}$ ama F, a utilidade de $M$ irádepender tanto do seu próprio nível de utilidade como do nível de F. De modo que quanto maior for o nível de utilidade obtido por $F$, maior será a utilidade obtida por $\mathbf{M}$.

No que diz respeito especificamente aos efeitos do amor sobre ocasamento, ele se reflete nos efeitos sobre a renda total e o produto gerado no casamento, via a redução dos custos de policiamento do contrato de casamento e pela importância dos bens produzidos pela família.

Segundo Becker (1974,p.14), o amor reduz a probabilidade de que o outro cônjuge furte-se de uma tarefa ou de se apropriar da produção familiar além do estabelecido no contrato matrimonial. Assim, dado que o amor e a preocupação com o cônjuge agem no sentido de reduzir ou eliminar a necessidade de policiamento, teremos um aumento da renda do casamento. De modo que quanto mais "apaixonado" estiver o casal, maior tenderá a ser a sua renda e maiores serão os benefícios advindos do casamento.

\subsection{As Formas de Casamento}

A questão fundamental formulada por Becker (1974), no que diz respeito às formas de casamento, é saber por que, embora as formas monogâmicas predominam hodiernamente, ainda se pratica a poligamia? e por que ela foi mais comum no passado que nos dias atuais?

Sobre os casamentos poligâmicos - poliandristas (uma mulher casada com dois ou mais homens) e poligenistas (um homem casado com duas ou mais mulheres) - Becker (1974,p.817-818) nos diz que esta última forma de casamento foi a mais comum devido ao fato de que a identidade do pai era conhecida e determinada.

Na poliandria, poderia existir o problema do "free-rider", no qual o marido iesfrutaria dos benefícios do casamento, mas poderia eximir-se de contribuir para o sustento da prole e de outras obrigações, esperando que outros o fizesseini, visto que não teria o mesmo incentivo para fazê-lo, se comparado com a poligamia ou a monogamia. Contudo tal análise deve ser qualificada no sentido de definir o número de participantes desta família, bem como as formas encontradas para que ele cumprisse o contrato naquela forma de casamento. Assim, é possível explicar, em parte, por que as uniões poligenistas predominaram e foram mais comuns que as poliandristas, pois foram mais eficientes, no sentido de implicarem em menores custos de fazer cumprir ("enforcement") do contrato matrimonial.

Quanto à questão do predomínio da forma monogâmica em relação à forma poligâmica, quando mantida a hipótese de retornos decrescentes devido a incor. poração de uma nova esposa à família, Becker $(1974, p .18)$ refere-se às diferenças 
quanto ao número de homens e mulheres na população e às diferenças de "produtividade" do homem. Quanto à primeira hipótese, quando há uma marcante diferença na taxa de sexos, a poligâmia tende a ser estimulada. Tal fato ocorre geralmente após as guerras, onde a população masculina é drasticamente reduzida. Na segunda hipótese, temos que o produto total referente a todos os casamentos poderia ser maior se fosse permitido o casamento de um homem mais "produtivo" com uma segunda ou terceira esposa. Esta análise explica, portanto, por que a poligênia tende a ser mais frequente naquelas sociedades marcadas por grandes diferenças econômicas, de prestígio e poder político.

\subsection{Teoria Econômica do Divórcio}

A teoria econômica do divórcio foi desenvolvida por Becker et alli (1977). Eles assumem que as pessoas se casam quando a utilidade esperada do casamento excede a utilidade esperada de permanecer solteiro. Assim, em decorrência desta hipótese, é assumido que o casal se separa quando a utilidade esperada do divórcio e de um possível casamento com outra pessoa for maior do que permanecer casada com a atual (cf. Becker, 1981,p.294-298).

A teoria econômica do divórcio é desenvolvida dentro de uma estrutura estocástica onde está presente a incerteza e a informação incompleta. Segundo Becker et alli (1977,p.1143), a incerteza está presente em todas as decisões e, entre estas está o casamento. Mesmo depois de um namoro prolongado, as pessoas recém-casadas enfrentam uma tremenda incerteza sobre as suas necessidades e as de seu cônjuge, da capacidade de ficar juntos, da fecundidade etc. Assim, quando o divórcio é analisado dentro de uma estrutura estocástica, ele seria função, basicamente, de dois fatores: (i) dos ganhos esperados do casamento e da (ii) distribuição de uma variável que descreva oc eventos inesperados; de modo que: quanto maiores forem os ganhos esperados do casamento e menor a variânuia dos ganhos inesperados, menor será a probabilidade de ocorrência do divórcio. Deste modo, com a introdução da incerteza e dos desvios entre as utilidades esperadas, eles reconciliam o fato de que há uma elevada utilidade esperada do casamento "ex-ante", mas uma baixa utilidade esperada "ex-post", quando da dissolução do mesmo.

JáMcKenziee Tullock (1980,p.141), enfatizam o fatode que odivórcio pode ser resultado de um "investimento insuficiente" na relação conjugal, tendo em vista uma avaliação equivocada dos recursos que deveriam ser investidos na sua continuidade, ou por que os custos de rever as cláusulas do contrato de casamento não compensariam os custos de permanecer casado.

Freiden (1974) destaca que o divórcio poderia ser interpretado como uma tentativa de correção de um "erro" cometido na escolha do cônjuge, estando esta 
correção sujeita a determinados custos, podendo ser estes institucionais, religiosos, psicológicos e econômicos.

Os principais resultados da teoria econômica do divórcio, scriam segundo Becker et alli (1977,p.1156-1157) os seguintes:

(i) um aumento no valor esperado das variáveis relacionadas na escolha do cônjuge, tais como a renda dos homens e a atratividade da mulher, reduz a probabilidade da ocorrência do divórcio e/ou aumenta a probabilidade do recasamento se dissolvido. A razão disto decorre de que os ganhos esperados do casamento irão aumentar na ocorrência daquelas variáveis;

(ii) um grande desvio entre o valor atual e o esperado, tais como as rendas e a fecundidade, aumenta a probabilidade do divórcio. A razão é que o ganho de tornar-se divorciado ou casar-se com outra pessoa aumenta mais que os ganhos de permanecer casado com o mesmo cônjuge;

(iii) um aumento na idade de casar tende a reduzir a probabilidade da ocorrência do divórcio. A razãoé que, quando as pessoas se casam com uma idade considerada avançada, os custos de procura são reduzidos, estando as mesmas relativamente bem informadas sobre si mesmas e sobre o mercado de casamentos;

(iv) um aumento no capital específico ao casamento, como as crianças e as práticas sexuais do cônjuge reduzem a probabilidade de dissolução do casamento. A razão é que os mesmos são considerados um capital específico tendo um valor menor em qualquer outro casamento ou quando divorciado;

(v) uma grande diferença entre as características dos cônjuges, tais como inteligência, classe social, religiãoe raça, aumentam a probabilidade de ocorrência do divórcio e diminuem a probabilidade de recasamento quando divorciado. A razão é que tais diferenças tende a reduzir os ganhos do casamciito;

(vi) a probabilidade do divórcio tende a declinar com a duração do casamento. A razão é que o capital específico ao casamento aumenta com a duração do mesmo.

\subsection{As Críticas à Teoria Econômica do Casamento e do Divórcio}

Nesta subseção, apresentamos as principais críticas dirigidas à teoria econômica do casamento e do divórcio.

Úma primeira crítica que é dirigida a abordagem econômica do casamento e do divórcio é que ela, em grande parte, ignora o "amor", que seria o principal 
motivo pelo qual as pessoas se casam. Como vimos na subseção 3.4, realmente os economistas nada teriam a dizer ou explicar por que uma pessoa ama a outra. Contudo, através da abordagem econômica do casamento e do divórcio, pode-se derivar implicações no que se refere aos seus efeitos sobre o casamento e o divórcio, que podem ser testadas empiricamente. Assim, embora o economista não tenha realmente nada o que dizer sobre o porquê uma pessoa ama outra, ele pode oferecer uma definição que é operacional do ponto de vista prático e oferecer hipóteses que podem ser testadas, bem como implicações que delas derivam.

Uma outra crítica é que a abordagem econômica seria muito limitada, visto que, muito mais que a maximização racional estaria envolvida no namoro, casamento e divórcio. Na realidade, este tipo de crítica reflete uma falta de compreensão da abordagem metodológica utilizada por estes autores. Na verdade, eles reconhecem que, realmente, muito mais estaria envolvido naquelas relações. Entretanto, para que se possa explicar, de maneira considerada satisfatória, tais fatos, eles utilizam a abstração, procurando evidenciar os aspectos mais relevantes para chegar a conclusões e previsões que podem ser bastante realistas. Assim, não seria intenção da abordagem econômica captar toda a complexidade e riqueza que envolve a relação amorosa, o casamento e o divórcio, mas sim de oferecer uma exp̄licação plausível e que a mesma possa ser testada; portanto a ausência de "realismo" dos seus modelos não invalidariam tal enfoque, mas seria essencial a ele (cf. Friedman, 1953).

Outra crítica dirigida a este enfoque é a de que, mesmo reconhecendo que os economistas tenham conseguido explicar, em parte, entre outras coisas, o casamento, o namoro e o divórcio, utilizando somente os instrumentos de análise econômica, tal enfoque não consegue gerar "implicações surpreendentes ou insuspeitas", isto é, para fatos cuja predição a teoria não foi especificamente elaborada, sendo, portanto, na linguagem de Lakatos, um programa de investigação científico teoricamente regressivo, mesmo que possa ser empiricamente progressivo. Isto até certo ponto pode ser verdade, contudo deve-se ponderar que tal abordagem é relativamente recente, sendo de se esperar que dentro de alguns anos surjam novas prediçōes e implicaçōes insuspeitas.

Por fim, é dito que tal teoria emprega um aparato teórico sofisticado para chegar a conclusões que, na maioria das vezes, são bastante óbvias. Entretanto, como pondera Becker $(1981$, p.11), o uso daquele instrumental é necessário a fim de obter-se uma avaliação correta da abordagem econômica. Além disso, mesmo que tais proposições sejam realmente triviais, a abordagem econômica não poderia furtar-se de oferecer uma explicação para tal.

\section{CONSIDERAÇÕES FINAIS}

Oobjetivo deste artigo foi o de fazer uma breve resenha da teoria econômica do casamento e do divórcio, desenvolvida principalmente na segunda metade dos anos 70 , a partir dos trabalhos de Becker $(1973,1974)$. Esta teoria é uma aplicação 
dos principais postulados da análise neoclássica a fatos que ocorrem fora do setor mercado e que não envolvem necessariamente preços monetários, aplicados a formação e à dissolução da família.

Pelo que foi visto nas seções precedentes, pode-se concluir que tal abordagemé capaz de oferecer interessantes "insights" e uma estrutura de análise bastante satisfatória para a análise do casamento e do divórcio, além de oferecer uma série de hipóteses eimplicações que podem ser refutadas, como evidenciam os trabalhos de Freiden (1974) e Keeley (1977), entre outros.

\section{BIBLIOGRAFIA}

BECKER,G. Irrational Behaviour and Economic Theory Journal, of Political Economy, v. 70, n. 1, p. 1-13, 1962. . A Teory of Marriage: Part I. Journal of Political Economy, v.81, n 4, p. 813-884, 1973. A Teory of Marriage: Part II. Journal of Political Economy, v.82,n.2, p.11-26, 1974 . Tratado Sobre la Familia Madri: Alianza. 1981.

1986

The Economic Approach to Human Behaviour. In: Ester, J. Rational Choice Oxford: Basil Blackwell,

Family, In: EATWELL., J.; MILGATE, M \& NEWMAN, P. The New PaIgrave Dictionary of Economics. London: Macmillan, 1992.

Family Economics and the Macro Behaviour. American Economic Review, v.78, n.1, p. 1-13, 1988.

BECKER,G.; LANDES,E.M e MITCHAEL,R.T. An Economic Analisys of Marital Instability Journal of Political Economy, v.85, n.6, p.141-1187, 1977.

BEN-PORATH,Y. Economics and the Family - Mattr or Mismatch? A Review of Becker's A Trcatise on the Family Journal of Economic Literature, v. 30, n 1 , p. 52-64, 1982.

BLAUG,M. The Methodology of Economics. Cambridge: Canbridge University Press, 1980.

EHRLICH,I. The Deterrement Effect of Capital Punishment: A Question of Live and Death. American Economic Review, v.65, n.1, p 397-417, 1975

EKEL.UND,R B. e HEBERT,R F A History of Economic Theory and Method McGraw Hill, 1990.

FREIDEN.A. The United States Marriage Market Journal of Political Economy, v.8,n.2, p. s34-s53, 1974

FRIEDMAN,M. The Methodology of Positive Economic. In: FRIEDMAN,M Essay in Positive Economics. Chicago: University of Chicago Press, 1953

HAMERMESH,D e SOSS.NM. An Economic Teory of Suicide. Jounal of Political Economy, v84, n. 1, p 8389.1974

HANNAN,M Families. Markets, and Social Structures: An Essay on Becker's A Treatise on the Family Journal of Economic Literature, v 20, n. 1,p.65-72, 1982

HUNT, E. K. História do Pensamento Fconômico. Rio de Janeiro: Campus, 1982

KEELEY,M.C. The Economic of Family Formation Economic Inquir; v. 15, n. 2, p. 238-250, 1977.

McKENZIE,R.B e TUL.L.CK,G. La Nueva Frontera de ia Economia Madri: Espasa-Calpe, 1980.

STIGLER,G J (1961). The Economics of Information Journal of Political Economy, v.65, n. 3, p. 213-255, 1961.

.Memórias de um Economista de Chicago. Porto Alegre, Ortiz, 1991

\section{ABSTRACT \\ THE ECONOMIC THEORY OF MARRIAGE AND DIVORCE}

The objetive of this article is to do a brief survey about the economic theory of marriage and divorce, showing their main assumptions, conclusions and critics. 